\title{
REFLEXIONES SOBRE E. BONETE (2019). EL MORIR DE LOS SABIOS. UNA MIRADA ÉTICA SOBRE LA MUERTE
}

\author{
REFLECTIONS ON E. BONETE (2019). EL MORIR DE LOS \\ SABIOS. UNA MIRADA ÉTICA SOBRE LA MUERTE
}

David González Niñerola ${ }^{a}$

Enrique Bonete Perales (Valencia, 1959) es catedrático de Filosofía Moral de la Universidad de Salamanca. Especialista en el campo de la ética y la filosofía política, también es autor, entre otras muchas obras, de títulos como Aranguren, la ética entre la religión y la política (1989), Éticas contemporáneas (1990), La faz oculta de la modernidad (1995), Éticas en esbozo (2003), ¿Libres para morir? (2004), Repensar el fin de la vida (2007), Ética de la dependencia (2009), Neuroética práctica (2010), Poder político: límites y corrupción (2014), Tras la felicidad moral (2015), Filósofos ante Cristo (2016, 2. ${ }^{\text {a }}$ edición ampliada) o La maldad, raíces antropológicas, implicaciones filosóficas y efectos sociales (2017). Articulista habitual en revistas especializadas de este campo académico, ha coordinado igualmente varios trabajos colectivos como Éticas de la información y deontologías del periodismo, en 1995, o Ética de la comunicación audiovisual, del año 2000.

Tal y como afirma el libro del Eclesiástico, "No alabes a nadie hasta el momento de su muerte, porque solo en su final se conoce al hombre" (Eclo, 11, 28). En esta obra dedicada con gran cariño, entre otros, al filósofo Javier Muguerza, se escudriña la muerte y vida -por este orden- de veinticuatro

\footnotetext{
${ }^{a}$ Facultad de Filosofía y Ciencias de la Educación. Universitat de València.

E-mail: davdgoni@gmail.com
} 
exponentes reconocidos de nuestra historia del pensamiento. Su estructura permite ambas cosas: conocer a cada hombre por su final y cotejar la coherencia íntima que a sus pensamientos en vida sobre la muerte se les puede reconocer.

En la parte introductoria que prologa estas páginas, titulada "Ética sobre la muerte", el autor deja en claro lo necesario de la "Tánato-Ética", una nueva perspectiva teórica tan ligada a la "Tanato-logía" como la bioética a la biología. Su campo de investigación propio sería bifurcable en dos niveles claramente distintos: uno más cercano a las dimensiones morales que se inscriben en el proceso final de la vida humana -y así adecuado al contexto médicohospitalario-, lo que llamaríamos una "Ética del [...bien...] morir", y otro inserto en el marco crítico de la filosofía moral como disciplina, más orientado a pensar las implicaciones éticas que conlleva la realidad incontestable de la finitud humana: una "Ética de la muerte". La primera busca establecer los principios morales que puedan orientarnos en la toma de decisiones prácticas; la segunda, "reflexionar, apoyándose en la historia del pensamiento occidental, sobre el significado ético de la realidad mortal del hombre", tal y como afirma el propio Bonete en El morir de los sabios, en adelante MS (p. 14). Porque la muerte tiene algo que decirnos sobre la vida, “[...] el afán de vivir y no morir determina sustancialmente la existencia personal e interpersonal, y de modo especial su vertiente ética. Hasta tal punto que, sin la fuerza configuradora de la muerte, la vida de cada cual (y la de todos juntos) carecería de valor y seriedad" (p. 17). Es el objeto de este libro, que tendrá una estructura tripartita.

La primera parte del $M S$ se articula en torno a investigar si es posible verdaderamente una mirada serena sobre el desenlace fatal de la vida, qué actitudes vitales podrían ser más idóneas ante su perspectiva y cómo deberíamos vivir o no, esta amenaza e incertidumbre continua que pesa sobre el hombre. Bajo el título “Ante la muerte: ¿Serenidad o temor?”, Enrique Bonete reflexiona de la mano de pensadores clásicos como Epicuro o Cicerón, y ya modernos como Descartes o Spinoza. No han sido los únicos que pudieran hoy denominarse clásicos... Max Scheler, Martin Heidegger o Ludwig Wittgenstein también se enfrentaron a su desafío con la misma profundidad que ellos, e igualmente Eugenio Trías, al que el autor dedica un octavo lugar. 
Superar el temor a morir y aprender a hacerlo es algo que ya reclama Sócrates en el Fedón platónico. La muerte tiene aquí el sentido de una liberación profunda, y el apego a esta vida el de la auténtica esclavitud. El estoicismo, y Cicerón como representante significativo, coinciden en este postulado, si bien partiendo de enfoques peculiares. Algo parecido sucede con Lucrecio, discípulo de Epicuro, para quien, literalmente, "es claro que nosotros nada debemos temer en la muerte, y que no puede llegar a ser desgraciado quien no existe" (p. 20) desde una óptica materialista -la propia del hedonismobastante más alejada de las dos anteriores. Epicuro de Samos es el primer autor que inaugura este amplio recorrido. Expondremos su desarrollo, lo mismo que el apartado dedicado a Cicerón, como dos pinceladas sintéticas que sirvan como muestra de la excelente técnica didáctica que Enrique Bonete ha concebido para esta obra: asistir primero como testigos al instante final de cada autor estudiado y, en segundo lugar, como espectadores críticos de su pensamiento en vida sobre el sentido ético y filosófico que vislumbraron acerca de la muerte. Con esta intención, el autor ha seleccionado en cada caso unos pocos -y breves- textos escogidos de cada filósofo, algo que ayuda magníficamente a efectuar una lectura y comprensión ágil, haciendo fácil acompañarle en esta panorámica total de unas trescientas páginas y convierte su lectura en un placer.

El fundador de la llamada "escuela filosófica del Jardín" nace solo siete años después de la muerte de Platón en el 341 a. C, y morirá como ha pensado y vivido hasta su vejez (270 a. C), sereno y sin miedo a pesar del dolor que le acompaña en su momento. Fue coherente con su pensamiento, para el cual "dada la estructura antropológica, basada en las sensaciones de dolores y placeres, no hay por qué temerla [...la muerte...] puesto que estar muerto equivale a no sentir ya ningún tipo de malestar ni bienestar" (p. 53). Efectivamente, para el iniciador de este hedonismo clásico, la felicidad última del hombre consistía en la experiencia del placer y la huida del dolor, algo solo perceptible sensorialmente; dada la insensibilidad que acompaña el factum de la muerte, es absurdo tenerle miedo salvo por el sufrimiento que pueda acompañarnos en el instante de dicho tránsito. Su muerte personal se detalla magistralmente como el ejemplo que fue de serenidad y paz espiritual, rodeado de quienes le amaron y apreciaron en vida. Schopenhauer o Montaigne lo 
alabarán todavía, diecinueve siglos después, como el mayor exponente de un hedonismo ascético paradigmático, capaz de refrendar consistentemente lo contradictorio de temer la experiencia mortal. Su fallecimiento, a pesar del dolor, habría sido, en palabras del autor, una "muerte irreal" (p. 49). La exposición detallada, amplia, de este materialismo del placer y del dolor que comienza la primera parte de nuestro libro es de las más bellas. "Vivid alegres y recordad mis doctrinas" fue la última de las sentencias del filósofo, tal y como recogió la tradición posterior y Diógenes Laercio en su Vida y opiniones de los filósofos ilustres.

Un segundo filósofo, estoico, ocupa el capítulo siguiente. Marco Tulio Cicerón (106 a. C.-43 a. C.) fue otro gran ejemplo de impasibilidad ante el desenlace final justo antes de ser ejecutado por orden del general romano Marco Antonio, tras la caída de Julio César. Sus últimas palabras antes de morir, "Siempre he sabido que soy mortal", son las de un pensador heredero del estoicismo griego. Se había enfrentado al militar, en sus famosas catorce Filípicas, acusándole de traición al pueblo y al Senado de Roma. La venganza no se hizo esperar. Nuestro autor relata su muerte y filosofía con el mismo detalle y exquisitez que en el caso de Epicuro y el resto de autores. Para el estoicismo, entregado "a vivir de acuerdo con la razón" (p. 63), el universo en su conjunto está regido por unas leyes naturales a las que no escapa nuestra biografía, ya escrita igualmente de antemano por aquel Logos (Ley cósmica) equiparable a la voz de los dioses que todo lo dominaría, desde el movimiento de los astros hasta nuestro nacimiento, avatares individuales y muerte. La vida humana tendría algo también de destino trágico al que todo hombre debe plegarse, incluyendo "morir con la entereza de un hombre sabio" (p. 63). Cicerón era consciente de que su momento había llegado y lo aceptó con entereza sapiencial. Bonete Perales expone magistralmente este episodio y la conexión con su pensamiento a través de otra selección de textos muy representativos: de las Consolationes, obra redactada tras el fallecimiento de su hija en que se ilustra la forma de afrontar un trance similar, a partir del De Senectute -magnífico tratado sobre la ancianidad como preparación dulce ante el final-y las Tusculanas, escrito sobre el año 45 a. C. pocos años antes de morir. En este último texto el filósofo expone sus argumentos a favor de perderle el miedo a la consumación de la vida -alguno de los cuales encuentra fundamento en la 
teoría epicúrea de la insensibilidad-. Marco Tulio Cicerón también albergaba una esperanza que conecta indefectiblemente con el platonismo de la Edad Antigua: "la muerte no solo no es un mal, sino incluso un bien" (p. 63), en el caso de aceptar esa otra creencia, propia de los sabios, como es la esperanza de una vida mejor más allá de esta vida. Así piensa después Agustín de Hipona (p. 143), gran conciliador de platonismo y cristianismo a principios del año 500 de nuestra era.

La filosofía y teología medieval, desde la fe cristiana, recogerá siglos más tarde gran parte de esta tradición antigua dándole un sentido trascendente a la existencia humana que romperá de una vez para siempre con el epicureísmo, pero suscribirá lo razonable de su eliminar el miedo a morir como máxima moral. Enrique Bonete ha elegido a Descartes y Spinoza, el primero como iniciador y el segundo como representante acreditado, de una perspectiva moderna reseñable. Ocupan el tercer y cuarto lugar de esta primera parte.

Tanto uno como otro son exponentes claros del neoplatonismo que conectó con la Nuova Scienza del siglo XVII. René Descartes inicia la modernidad con su Discurso del método, en el cual esboza un modelo de moral provisional con fuertes tintes estoicos, desde una perspectiva confesionalmente católica sobre la muerte y un dualismo antropológico profundo: la inmortalidad del alma sobre lo corporal estaría fundamentada racionalmente y no solo desde la fe. Su "morir de frío" (p. 67), en palabras del autor, contrasta con la calidez de una esperanza de supervivencia a la aniquilación del cuerpo que también suscribirá Spinoza, continuador fiel de su pensamiento. "Amar la vida sin temer la muerte", el lema ético cartesiano, tendría sentido "al conocer que [... el hombre...] no está condenado a morir totalmente como los animales, sino que, por poseer un alma separada del cuerpo, le aguarda otro tipo de vida en comunión con Dios" (p. 73) -una realidad metafísica cuya existencia sería demostrable racionalmente, de modo incontestable y lógico-. Es muy significativa la correspondencia adjunta que el francés mantuvo con la princesa Isabel de Bohemia. Baruch Spinoza, fallecido veintisiete años después que su maestro, profundizará en la misma línea añadiendo sus matices a un cartesianismo filosófico de fondo. Una y otro apuntalan la misma pose del sabio clásico ante la mortalidad del género humano: una absoluta serenidad que les acompañó lógicamente hasta el final "si en el alma hay algo de la esencia eterna de Dios" (p. 89) que no puede morir. 
Al hilo de la "Introducción" citada al principio, nuestro autor justifica sólidamente el estudio de las otras cuatro aportaciones que concluyen esta primera parte de su libro: las de Max Scheler, Martin Heidegger, Wittgenstein y Eugenio Trías. Era preceptivo porque la filosofía más reciente ha criticado "la actitud dominante del s. xx que, al instalarse en la cotidianidad huye de la muerte, la esquiva y reprime por el pánico que le produce" (p. 22). La forma inesperada con que nos abandonó el primero de ellos en 1928 no le impidió impartir el invierno anterior un curso universitario dedicado solamente a $L a$ esencia de la muerte, una mirada fenomenológica sobre la misma que guarda coherencia con la reflexión que desarrolló durante años en su Ética acerca del mismo tema. La recopilación de textos Muerte y supervivencia que publicó su viuda cinco años después de morir es la otra gran fuente primigenia para el estudio de este filósofo genial al que Heidegger consideraba "la más vigorosa potencia filosófica en la Alemania de hoy, no, en la Europa de hoy, hasta en toda la filosofía actual" (p. 93). Él mismo ha sido otro genio al que Bonete dedica a continuación la extensión de doce páginas, algo merecido tras Ser y tiempo (1927), en que la muerte ocupa el centro de la realidad, y por haberse constituido en la "alma mater" del triunvirato existencialista posterior que comprenderá a Karl Jaspers (MS, Parte III), Jean Paul Sartre y Gabriel Marcel (pp. 177-86 y 195-205). Wittgenstein y nuestro pensador español, antes citado, acaban el primer gran grupo de filósofos: el austríaco, por su especial relevancia desde la reflexión sobre el suicidio -que condenará tajantementeo su tesis en el Tractatus de que "la muerte no es un acontecimiento de la vida", la importancia de las notas de su Diario filosófico, los Movimientos del pensar..., amén de la experiencia biográfica que le marcó para siempre en las trincheras de la Primera Guerra Mundial; Trías, por su "apuesta” y reflexiones acerca de la muerte a lo largo de toda su creación filosófica hasta el texto premiado de 2008 -"El gran viaje", excelente artículo publicado en La Tercera de $A B C$ el 4 de noviembre de ese año-.

La segunda parte de este ambicioso recorrido lleva por título "Ante el dejar de ser: ¿El yo propio o el otro amado?” y persigue responder a la pregunta por el impacto mayor o menor de la muerte con respecto a la pérdida de uno mismo o la del otro a quien amamos. Nuestra vida moral entra aquí de lleno en el círculo existencial de la muerte. O viceversa. Bonete no oculta su co- 
nocimiento particular de las teorías del norteamericano Thomas Nagel, ni su simpatía por las tesis del alemán Ernst Tugendhat (2002, 2004, 2008) (p. 25), para cuya lectura recomienda, asimismo, la del filósofo José Vicente Bonet en La pregunta más humana de Ernst Tugendhat (Bonet, 2013). El agustinismo expuesto al principio da mejor respuesta en el segundo sentido, junto al psicoanálisis, el existencialismo de Marcel o Julián Marías (pp. 215-225). Otros, en el primero. Aquí podríamos ubicar a Unamuno, Hannah Arendt o Xavier Zubiri.

Miguel de Unamuno y Jugo -"Morir en zapatillas” (p. 153)- escribió para su lápida los versos que mejor le explican, tanto en vida como en su muerte:

"Méteme, Padre Eterno, en tu pecho,

misterioso hogar,

dormiré allí, pues vengo deshecho

del duro bregar" (p. 155).

Este "duro bregar" no fue poca cosa. Su remedo de imperativo categórico al estilo kantiano para obrar de forma "que merezcas a tu propio juicio y a juicio de los demás la eternidad, que te hagas insustituible, que no merezcas morir. O tal vez así: obra como si hubieses de morirte mañana, pero para sobrevivir y eternizarte" (pp. 155 y ss.) arroja luz sobre el combate interior de un hombre que no suspiró al final de sus días por encontrar consuelo existencial en las entelequias de la razón humana, falible e indigna de crédito... En palabras del autor, para Unamuno "la teoría ética como tal es totalmente ineficaz para hacer a los hombres buenos, como lo es la estética para enseñar a expresar y sentir la belleza y la lógica para discurrir [...] La bondad humana depende más de la conciencia que se tenga del inevitable morir y del ferviente anhelo de existir que de cualquier otra consideración ética o cultural" (p. 156). Al rector de Salamanca no le faltaban ambas cosas. Trágicamente. Hizo de la muerte la piedra de toque para toda reflexión sensata. Bonete estudia a fondo esta dimensión central del discurrir unamuniano analizando por el camino incluso su concepción (relacionada directamente con la finitud) de la sexualidad humana, además de algunos fragmentos elegidos del Diario Íntimo. La "muerte propia" encontró otro modo de pensarse en la filósofa judía Hannah Arendt y Xavier Zubiri. Si en el caso de este último vale la pena su 
lectura directa ("Muerte solitaria", p. 187), en el de Hannah Arendt podemos adelantar algo, sin privar a quien se acerque a estas páginas de efectuar un acercamiento original y fresco.

A diferencia de las tesis heideggerianas que señalan la muerte como principal condición del existir humano, Arendt sitúa la natalidad como primera categoría del pensamiento en general -incluyendo el de tipo político-. Así lo expresa en el primer capítulo de La condición humana. Recibió la noticia de su galardón mientras escribía La vida del espíritu, obra inconclusa cuando fallece en 1975, de repente y rodeada de amigos mientras saboreaba sus queridos cigarrillos y un buen café. Había sido la filósofa de la libertad, algo que no evitaba, al mismo tiempo, su profunda conciencia de que "la muerte nos envuelve, nos rodea, hacia ella caminamos, o ella misma se acerca a nuestro vivir, como su esencia, norte, sustrato" (p. 206). Para Enrique Bonete, el pensamiento de Arendt apunta a concebir la muerte como una posibilidad, y el querer vivir como aquello que debemos salvaguardar para que nos sirva a modo de arma. Si el mejor espacio para nacer es la familia, como dejó negro sobre blanco, desde luego el mejor para morir era el de la amistad, cosa que se cumplió felizmente en su vida... En el decurso biográfico intermedio la persona es capaz de aportar algo inédito y único a la realidad, cosa que la muerte podrá detener pero no impedir, y constituye nuestra más alta esperanza. El filósofo Hans Jonas, en su funeral, pronunció las bellísimas palabras: “... sobresalió como un ser excepcional, único en un modo todavía indefinible" (p. 205). Martin Heidegger, secretamente enamorado de ella durante décadas, le dirigió después a su amigo, por correspondencia, la siguiente frase, tan hermosa como el discurso citado: "Hannah, centro de un gran círculo, cuyos rayos giran ahora en el vacío” (p. 207).

El capítulo “Ante el suicidio: ¿a favor o en contra?” es una reflexión tánato-ética que no podía hurtarse al debate y queda esbozada en el tercer y último bloque de esta antología filosófica. Si en las dos partes anteriores se contemplaba la muerte como inherente al ser antropológico, aunque experimentada de forma quizás un tanto exógena, como algo externo al hombre que se le impone por encima de su voluntad, queda aquí pensarla como fruto de un acto posibilitado por la propia libertad y forma del existir humano, y justificable o no, moralmente, como algo legítimo. Bonete Perales esclarece su fundamen- 
tación teórica, no tan de profundo conocimiento público, en torno a todo un universo conceptual del que se ha escrito mucho a lo largo de la historia del pensamiento. Nuestro catedrático salmantino de Filosofía Moral no pretende ocultarse tras este extenso recorrido filosófico, aportará también su propia posición, con la que estamos plenamente de acuerdo:

Matarse es casi matar a otro en cuanto que la vida moral de cada cual está unida ineludiblemente a los semejantes [...] Reivindicar el suicidio como acto de libre arbitrio de una persona equivale a reivindicar una ética individualista y "atomística", es decir, un ejercicio soberano y aislado de la libertad que ignora el dato antropológico y ético fundamental de que el ser humano solo adquiere su humanidad y moralidad viviendo y actuando ante, con y para otros (pp. 41 y ss.).

La pregunta por el sentido de nuestra existencia es la gran cuestión de fondo.

El episodio dedicado a Séneca, en la línea clásica del estoicismo, propone una visión a favor de abandonar voluntariamente esta vida que no se justificaría nunca, todo sea dicho, por razones que hoy muchos contemplan como sólidas -la enfermedad o el dolor, por ejemplo-. En dirección diametralmente opuesta, Santo Tomás de Aquino apunta la postura filosófica y teológica que asumirán la inmensa mayoría de universidades en Europa a partir de su publicación, en torno a 1274. El aquinate murió en circunstancias poco esclarecidas (¿envenenado?)... Un tercer lugar reservado a Michel de Montaigne (pp. 253-263) pone en claro la aparición de una síntesis interesante entre la fe cristiana, el estoicismo antiguo y un escepticismo confeso en pleno Renacimiento, sobre el año 1550. La muerte del compositor de los Ensayos, en medio de una Eucaristía y profundamente consolado por la fe en que había sido instruido, permite entrever un cierto fideísmo, pero su postura permisiva frente al suicidio añade también los matices de la consideración contraria por amor al prójimo, enfoque analizado deliciosamente por el autor.

El británico David Hume e Immanuel Kant se explican uno detrás del otro a continuación. Desde un empirismo estricto que contrasta con el racionalismo del alemán, Hume aboga por la imposibilidad de probar metafísica, moral o físicamente la inmortalidad del alma; eso no le impidió sugerir en sus obras 
un cierto fideísmo cristiano parecido al de Montaigne en que pudiera hallar acogida esta creencia frente a la muerte. De hecho, le concede al suicidio legitimidad moral amparándose -singularmente- en argumentaciones de tipo teológico y bíblico que consideran la Providencia divina y la libertad humana, la misión que Dios concede a cada hombre en esta vida o la ley divina que proscribe el homicidio. En Sobre el suicidio y otros ensayos se encierra la revelación de algunas de estas claves hermenéuticas. Su fallecimiento fue dulce, sin resistirse a lo inevitable de una enfermedad que llevó tan dignamente como para merecer un elogio público, y por escrito, de su íntimo amigo, el famoso economista Adam Smith.

Kant tuvo un desenlace muy similar al final de sus días. En Königsberg, a mediodía del 12 de febrero de 1804, falleció acompañado de los suyos, por quienes era considerado "el mayor filósofo prusiano" (p. 276). Tuvo tiempo también para prepararse y morir con serenidad. Fue mucho más intransigente que Hume en su opinión sobre el suicidio. Ya en la Metafísica de las costumbres mantuvo una crítica negativa del estoicismo antiguo, algo que "le parece a Kant contradictorio con la reiterada defensa estoica de la virtud de la fortaleza ante la adversidad" (p. 279) en palabras del autor. Lejos de justificaciones teonómicas, mantener la vida propia se sujetaría estrictamente a la posibilidad de mantener nuestra dignidad moral, algo que debería valorarse muy por encima de cualquier otra consideración. En sus Lecciones de Ética (versión original de 1875) da cuenta de cómo "el suicidio sobrepasa todos los límites del uso del libre arbitrio". Bonete recorre la teoría kantiana y sus puntos fundamentales a lo largo de diez páginas que clarifican su cadena de argumentaciones. Su valoración moral de este tipo de acto quedaba a expensas de los deberes para con uno mismo que todos debemos asumir. Otro binomio digno de mención es el correspondiente a los filósofos Arthur Schopenhauer y Friedrich Nietzsche. Ambos, antagónicos en sus teorías, se acercarán, sin embargo, en torno a este dilema ético: el de arrebatarse la vida. Para el autor de Parerga y Paralipómena podrá ser un error pero también un derecho; las tesis nietzscheanas son imprescindibles para comprender en su amplitud el debate actual en torno a la eutanasia. 
REFERENCIAS BIBLIOGRÁFICAS

Bonet, J. V. (2013). La pregunta más humana de Ernst Tugendhat (1. $\left.{ }^{\mathrm{a}} \mathrm{ed}\right)$. UPV.

Bonete, E. (2019). El morir de los sabios: Una mirada ética sobre la muerte. Tecnos.

Cicerón, M. T. (1999). Sobre la naturaleza de los dioses. Gredos.

Eclesiástico (2017). Biblia de Jerusalén (4. ${ }^{\text {a }}$ ed.). Desclěe de Brouwer.

Platón (2003). Apología de Sócrates. Fedón. Consejo Superior de Investigaciones Científicas.

Tugendhat, E. (2002). Problemas: Lenguaje, moral y trascendencia. Gedisa.

Tugendhat, E. (2004). Egocentricidad y mística: Un estudio antropológico. Gedisa.

Tugendhat, E. (2008). Antropología en vez de metafísica. Gedisa. 